\section{IN THE NEWS}

Vaccine cash plan

On 9 September, the UK chancellor, Gordon Brown, announced an international finance scheme to raise billions of pounds to fund the vaccination of children in the developing world against preventable deadly diseases, such as polio, hepatitis B and tetanus.

So far, the International Finance Facility for Immunisation (IFFIm), launched by Mr Brown has received backing from France, Italy, Spain and Sweden, which (together with the UK) have pledged to reach the target of UK£2.2 billion. Microsoft tycoon Bill Gates has promised the scheme a further £408 million over the next ten years and has said that it is "a bold and innovative approach to financing critical global health programs" (Bloomberg).

The money raised by IFFIm will be given to The Global Alliance for Vaccines and Immunization (GAVI) to push forward their vaccination programmes in the developing world. With this, Mr. Brown believes that "10 million lives will be saved in the next two decades" (The Guardian).

The scheme will involve borrowing money to give as developmental aid. The cash will not be included in official governmental borrowing figures but will be paid back later out of future aid budgets. But this 'buy now, pay later' scheme has received some criticism.

Although in favour of increasing funding for vaccination, Peter Hardstaff, from the World Development Movement, is concerned that "because the IFF is a way of borrowing money from the international finance markets, in years to come we're going to end up using aid money to pay off the interest to financiers rather than helping the poor" (BBC News). He argued that it would be better for the schemes to be funded from ordinary government revenue.

Lucy Bird

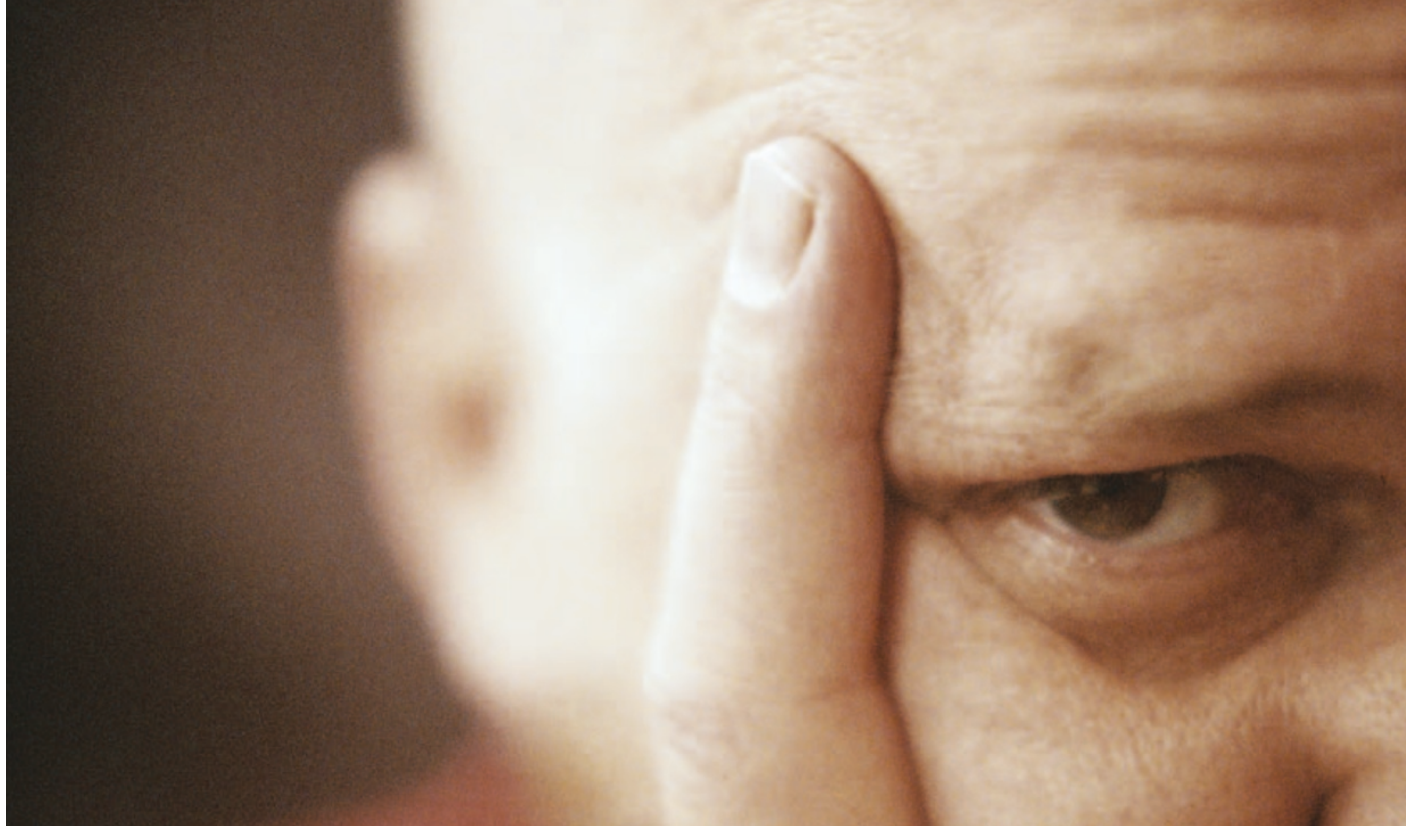

ANTIVIRAL IMMUNITY

\title{
Stressed mitochondria take it out on viruses
}

The identification of a new protein that coordinates the production of type I interferons (IFNs) in response to viral infection is reported in Cell. The unusual mitochondrial localization of this protein indicates that there might be links between the innate immune and apoptotic responses, with mitochondria extending their role as sentinels of cellular stress.

The transcription factors nuclear factor- $\mathrm{kB}$ $(\mathrm{NF}-\kappa \mathrm{B})$ and IFN-regulatory factor 3 (IRF3) are essential for type I IFN production in response to RNA viruses, operating downstream of the receptors Toll-like receptor 3 and the recently identified retinoic-acid-inducible gene I (RIG-I). However, the mechanisms by which RIG-I activates NF- $\mathrm{KB}$ and IRF3 are not clear, so the authors looked for other proteins containing caspase-recruitment domains (CARDs) similar to those of RIG-I that might be involved in this pathway. One protein with a single CARD at the amino terminus, a central proline-rich region and a hydrophobic transmembrane domain at the carboxyl terminus was identified and was named mitochondrial antiviral signalling protein (MAVS) on the basis of the following properties.

Overexpression of MAVS by HEK293 cells activated a luciferase reporter under control of the IFNA or IFNB promoter, and MAVS was also shown to induce the production of endogenous IFN- $\beta$ at both mRNA and protein levels. This correlated with activation of both IRF3 and NF- $\kappa \mathrm{B}$. When the expression of endogenous MAVS was inhibited by RNA interference (RNAi), both NF- $\mathrm{KB}$ and IRF3 activation, and therefore IFN production, were abolished in response to the single-stranded RNA virus Sendai virus.

The decrease in IFN production in response to viral RNA that was caused by RNAi-mediated inhibition of MAVS increased both viral titres and the sensitivity of cells to killing by vesicular stomatitis virus, showing the physiological importance of the MAVS-mediated innate antiviral pathway.

Some of the details of this pathway were elucidated by showing that, whereas RNAi-induced knockdown of MAVS blocked induction of IFN- $\beta$ expression by RIG-I, RNAi-induced knockdown of RIGI did not inhibit induction of IFN- $\beta$ expression by MAVS, which indicates that MAVS lies downstream of RIG-I. Further experiments showed that MAVS lies upstream of the inhibitor-of-NF- $\mathrm{KB}$ kinase IKK and the IRF3 kinase TBK1.

The transmembrane region of MAVS resembles that of several mitochondrial proteins, including apoptotic regulators of the BCL-2 family. Indeed, confocal microscopy and subcellular-fractionation experiments showed that MAVS colocalizes with the anti-apoptotic protein BCL- $\mathrm{X}_{\mathrm{L}}$ in the outer mitochondrial membrane. Mutant MAVS proteins that lacked the transmembrane domain and became cytosolic or that were targeted to different membrane locations, such as the plasma membrane or endoplasmic reticulum, had a markedly reduced ability to induce IFN- $\beta$ expression, showing the importance of mitochondrial localization for the antiviral function of MAVS.

MAVS is therefore the first example of a mitochondrial protein that has a role in innate immunity and that activates NF- $\mathrm{KB}$ and IRF3. The authors suggest that mitochondria can integrate signals from cellular stresses such as viral infection - with MAVS being ideally located to detect viral replication on intracellular membranes - to induce an immune or apoptotic response depending on the challenge.

Kirsty Minton

Q) References and links

ORIGinal Research PAPER Seth, R. B., Sun, L., Ea, C.-K. \& Chen, Z. J. Identification and characterization of MAVS, a mitochondrial antiviral signaling protein that activates NF-KB and IRF3. Cell 122, 669-682 (2005) 